\title{
A cultura da mandioca: os efeitos da correção do solo sobre suas características agronômicas, distribuídas em épocas distintas
}

\begin{abstract}
O estado do Pará e o principal produtor de raízes de mandioca do Brasil, onde seu cultivo é realizado majoritariamente por pequenos produtores, apesar de o estado apresentar maior produtividade em relação a outros estados produtores, sua baixa eficiência produtiva está ligada a alguns fatores, principalmente ao manejo da cultura e a baixa fertilidade dos solos utilizados para cultivo da mandioca. Com objetivo de avaliar as características agronômicas da cultura da mandioca de mesa (Manihot esculenta crantz), submetidas a aplicação de calcário dolomítico. Instalou-se um experimento sob condições de campo na Universidade Federal Rural da Amazônia, localizada no município de Belém-Pará. Para o estudo utilizou-se o material vegetativo de mandioca de mesa da variedade manteiguinha amarelinha. O delineamento experimental adotado foi em blocos ao acaso, com 5 tratamentos e 5 repetições, os tratamentos consistiram na aplicação de calcário em diferentes épocas e doses na área de plantio, as unidades experimentais foram compostas de parcelas com dimensões de $1,8 \mathrm{~m}$ de largura e $6 \mathrm{~m}$ de comprimento aplicação de calcário em diferentes épocas e doses na área de plantio, as unidades experimentais foram compostas de parcelas com dimensões de $1,8 \mathrm{~m}$ de largura e $6 \mathrm{~m}$ de comprimento espaçadas em 0,90m entre linhas e 1,0 m entre plantas, totalizando 12 plantas por unidade amostral. Os tratamentos constaram de aplicação de calcário em duas épocas antes e na ocasião aplicação de calcário 1,644 kg ha-1 + 20\% na ocasião do plantio; T5 aplicação de calcário 1,644 kg ha-1 +60\% kg ha-1 na ocasião do plantio. Aos 180 dias após o plantio (DAP), foi realizada a colheita para coleta de dados fitométricos, utilizando-se 2 (duas) plantas centrais do interior de cada parcela para avaliação de massa fresca da parte aérea: número de folhas; massa fresca da folha; massa fresca da raiz. Para determinação de matéria seca utilizou-se raiz, caule e folha. Verificou-se que para a maioria das variáveis analisadas aos 180 DAP, não obtiveram respostas significativas para ao teste de Turkey a 0,05 de significância, para a maioria dos caracteres como: altura da planta, diâmetro do caule, número de folhas, peso massa fresca da folha, número de raízes totais, comprimento de raiz. Apresentado diferença estatística exceto para a caractere peso massa fresca caule, número de raiz comerciais, peso de raiz comercial, peso de raiz totais, massa seca folha, massa seca caule, massa seca de raiz totais.
\end{abstract}

\section{The cassava crop: the effects of soil correction on its agronomic characteristics, distributed at different times} \begin{abstract}
The state of Pará is the main producer of cassava roots in Brazil, where its cultivation is mainly carried out by small producers, although the state has higher productivity compared to other
producing states, its low productive efficiency is linked to factors, mainly to the management and low fertility of the soils used for growing cassava. In order to evaluate the agronomic producing states, its low productive efficiency is linked to factors, mainly to the management and low fertility of the soils used for growing cassava. In order to evaluate the agronomic
characteristics of the table cassava culture (Manihot esculenta crantz), submitted to the application of dolomitic limestone at different times. An experiment under field conditions was characteristics of the table cassava culture (Manihot esculenta crantz), submitted to the application of dolomitic limestone at different times. An experiment under field conditions was
installed at the Federal Rural University of Amazonia, in the municipality of Belém-Pará. The buttery yellow variety was used. The experimental delineation adopted was in blocks at random with 5 treatments and 5 repetitions, the treatments consisted of application of limestone at different times and doses in the planting area, the experimental units were composed of plots with dimensions of 1,8 wide and $6 \mathrm{~m}$ long spaced in $0,90 \mathrm{~m}$ between lines and $1.0 \mathrm{~m}$ between plants, totalling 12 plants per sample unit. The treatments appeared of application of limestone in two seasons before and at the time of planting: T1 without silage; T2 heating 30 days before planting with application of limestone 1,644 kg ha-1, T3 heating at planting with application of limestone 1,644 kg ha-1; T4 application of limestone 1,644 kg ha-1 + 20\% at planting; T5 application of limestone 1,644 kg ha- $1+60 \%$ ha- 1 at planting. At 180 days after planting (DAP) the collection was carried out for the collection of phytometric data, using 2 (two) central plants within each plot for the evaluation of fresh mass of the aerial part: number of leaves; Fresh leaf dou Tuf dough. For the de Turkey test at 0.05 significance, for most characters such as: plant height, stem diameter, number of leaves, weight of fresh leaf mass, number of total roots, root length. Presented statistica
difference except for the character weight fresh stem mass, number of commercial root, commercial root weight, total root weight, dry leaf mass, dry stem mass, dry total root mass.
\end{abstract}

Keywords: Manihot sculptures Crantz; Table mandioca; Silage; Productivity

Wagner dos Santos Ramos (iD)

Universidade Federal Rural da Amazônia, Brasil

http://lattes.cnpq.br/3766496596668920

http://orcid.org/0000-0002-5297-8129

wagner.ramos@ineaf.ufpa.br

Juliete de Sousa Oliveira (D)

Universidade Federal Rural da Amazônia, Brasil

http://lattes.cnpq.br/8187930333351354

http://orcid.org/0000-0002-6876-9823

juliete.soliveiras@gmail.com

Leonardo Elias Ferreira (iD

Universidade Federal da Paraíba, Brasi http://lattes.cnpq.br/9716950171771254 http://orcid.org/0000-0001-8854-8545

leonardo.ferreira@ufra.edu.br
Jessivaldo Rodrigues Galvão (iD

Universidade Federal Rural da Amazônia, Brasil

http://lattes.cnpq.br/0013591065769741

http://orcid.org/0000-0003-4242-6555

jessigalvao50@gmail.com

Danielle Pereira Mendonça

Universidade Federal Rural da Amazônia, Brasil

http://lattes.cnpq.br/6344169083897136

http://orcid.org/0000-0003-4641-1748

daniellepereiraam@gmail.com

Jhon Anderson Chaves de Araujo (if

Universidade Federal Rural da Amazônia, Brasil

http://lattes.cnpq.br/5884975318468097

http://orcid.org/0000-0002-8275-4919

jhon.anderson.araujo@gmail.com
Amanda Leal de Souza (iD)

Universidade Federal Rural da Amazônia, Brasil

http://lattes.cnpq.br/2186744639987280 http://orcid.org/0000-0002-0106-7624 amandaleal.agro@gmail.com
Referencing this:

RAMOS, W. S.; OLIVEIRA, J. S.; FERREIRA, L. E.; GALVÃO, J. R.; MENDONÇA, D. P.; ARAUJO, J. A. C.; SOUZA, A. L.. A cultura da mandioca: os efeitos da correção do solo sobre suas características agronômicas, distribuídas em épocas distintas. Revista Ibero Americana de Ciências Ambientais, v.12, n.7, p.15-24, 2021. DOI: http://doi.org/10.6008/CBPC2179-6858.2021.007.0002 


\section{INTRODUÇÃO}

A mandioca (Manihot esculenta Crantz) é uma planta de origem sul-americana, pertencente à família das Euphorbiaceas, no Brasil seu país de origem, a cultura está presente em todo território nacional, sob as mais diferentes condições edafoclimáticos (SILVA, 2014). A planta de mandioca destaca-se dentre as tuberosas, por tratar-se de uma cultura amplamente cultivada por mais de 100 países tropicais, sendo uns dos alimentos mais consumidos na dieta humana no mundo (FAO, 2013). Vindo a constituir uma das principais fontes alimentícia e energética para populações mais carentes, principalmente em países em desenvolvimento (MODESTO JÚNIOR et al., 2016).

No Brasil, a cultura tem importância relevante no cenário socioeconômico do país (FERREIRA FILHO et al., 2013). A exploração da cultura nas regiões brasileiras, ocorre majoritariamente, por pequenos agricultores familiares, com usos da baixa aplicação tecnológica, por ser uma cultura rústica, característica esta que vem a favorecer sua grande capacidade adaptativa aos mais diferentes climas presentes no país, obtendo desempenho satisfatórios em solos ácidos e de baixa fertilidade (SILVA, 2014).

As raízes de mandioca constituem uma das principais fontes de carboidratos, e rica fonte de amido, sendo utilizadas no beneficiamento de seus derivados como fécula e farinha (ALBUQUERQUE et al., 2012). Valle (2010), Aguiar et al. (2011) e Martins et al. (2018), destacam a mandioca de mesa como um dos produtos hortícolas mais consumidos em todo Brasil, principalmente na forma in natura, sendo amplamente utilizado para fins culinários com o mínimo de processamento, por apresentar características sensoriais desejáveis como sabor adocicado, reduzido tempo de cozimento, alto teor de massa, poucas fibras, apresentando concentração de compostos cianogênicos menor de 100 mg kg-1 de polpa fresca.

Segundo a Companhia Nacional de Abastecimento, a produção de nacional de raízes de mandioca, no ano no 2017 , foi de 20,60 milhões de toneladas, cultivadas em uma área plantada de $1.407,345$ milhões/ha. (CONAB, 2017). A Região Norte, mesmo ocupando extensas áreas plantadas, tendo atualmente a maior produção de mandioca do país, ocupa a 4a posição no ranking de produtividade, com 15.280,61 kg/ha-1. Dentre os estados brasileiros produtores de raiz, o estado do Pará destaca-se como maior produtor de raízes no ano de 2017, com produção agrícola de 4.23 milhões de toneladas de raízes, produzidos em uma área de 295,137 hectares, contribuindo com a participação de 20,55\% na produção nacional brasileira, seguidos pelos estados do Paraná com 3,04 e Bahia com 2,07 milhões de toneladas, respectivamente (EMBRAPA, 2018).

Mesmo o estado do Pará destacando-se como principal produtor de raízes de mandioca sobre outros estados produtores, esses números não são sinônimos de eficiência produtiva, pois, sua produtividade baixa em torno de 14.34 t/ha, valor observado abaixo da média nacional que e de 14.64 t/há (EMBRAPA, 2018).

Um dos principais fatores que leva o Pará a ter baixa eficiência produtiva dos mandiocais paraenses está relacionado aos sistemas produtivos empregados, com uso de práticas culturais rudimentares do manejo e fertilidade dos solos utilizados para o cultivo da mandioca, vistos que, grande parte de classes de solos presentes na região são caracterizados por baixa fertilidade natural, com elevadas concentrações de 
alumínio, classificando-os como solos ácidos (ALVES et al., 2008).

Neste contexto a prática da calagem com uso de calcário, destaca-se como prática indispensável aos cultivos, por ter a finalidade de adequar a faixa de $\mathrm{pH}$, diminuindo a acidez do solo, repondo ao solo macronutrientes como Cálcio e Magnésio, favorecendo a absorção de nutrientes disponíveis no solo pela planta, proporcionando o bom desenvolvimento de características agronômicas da cultura (SERRAT et al., 2002; CAMPOS et al., 2013). O objetivo do trabalho é avaliar as características fitométricas e produtividade de raízes da cultura da mandioca de mesa submetida a aplicação de calcário dolomítico.

\section{MATERIAIS E MÉTODOS}

O experimento foi conduzido em campo na área experimental do Instituto de Ciências Agrárias (ICA), da Universidade Federal Rural da Amazônia (UFRA), campus Belém-PA no período de junho a dezembro de 2018. O município está localizado a ( $1^{\circ} 27^{\prime}$ latitude Sul; 48 26’ longitude Oeste), com altitude média de 162 metros. O solo, pelo sistema brasileiro de classificação de solos, EMBRAPA (2018) foi classificado como Latossolo Amarelo Distrófico, textura média.

De acordo com classificação de Köppen, o clima da região é do tipo (Af), caracterizado por Clima Equatorial, com temperaturas médias anuais de 25,9 a $32{ }^{\circ} \mathrm{C}$, o período de maior pluviosidade está entre os meses de dezembro a maio (KOTTEK et al., 2006). Os dados climatológicos do período de execução do experimento foram fornecidos pelo grupo de Pesquisa Integração Solo-Planta-Atmosfera na Amazônia ISPAAm da Universidade Federal Rural da Amazônia - UFRA, estão descritos na (Figuras 1 e 2).

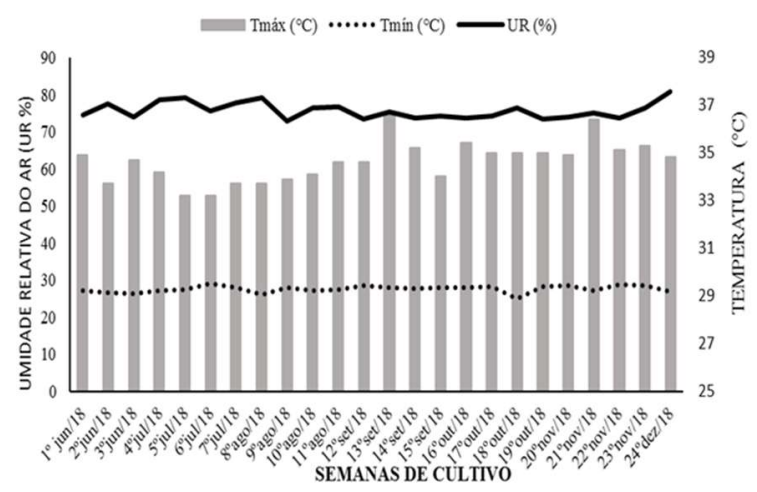

Figura 1: Temperaturas máximas, mínimas (으) semanais, umidade relativa do ar (UR), no período dos meses de junho a dezembro de Belém-PA, 2018.

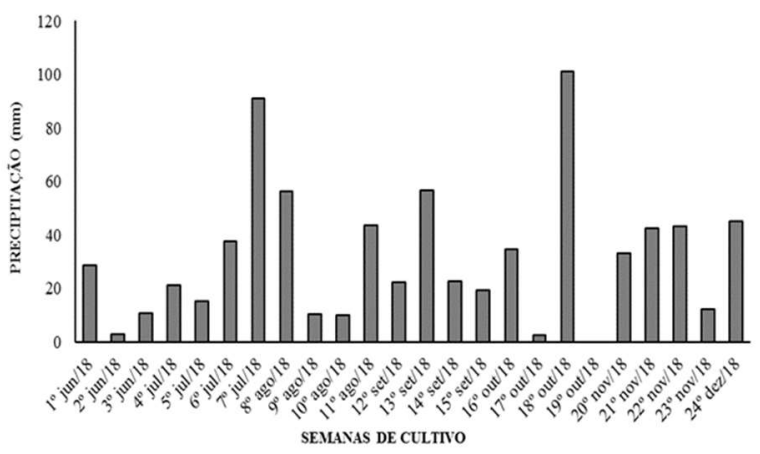

Figura 2: Médias semanais de precipitação (mm), junho a dezembro, Belém-PA, 2018.

Antes da instalação do experimento foi realizada a amostragem do solo para fins de análise de fertilidade, adotou-se metodologia descrita por Brasil (2010), Cravo (2010) e Veloso (2010). A coleta de solo ocorreu 60 dias antes do plantio, onde foram coletas no total de 20 amostras simples na camada arável na profundidade de $0-20, \mathrm{~cm}$ com auxílio de trado holandês. Os resultados da análise química do solo estão descritos na Tabela 1.

$\mathrm{Na}$ área experimental (Figura 3), foram realizadas inicialmente uma capina mecânica e, vinte dias antes do plantio, uma capina química com aplicação de herbicida seletivo, conjuntamente, ROUNDUP (Glifosato) + FLUMYZIM (Flumioxazina), nas proporções de 150mg e 4g, respectivamente, diluídos em 201 de 
água, aplicada com aparelho pulverizador costal em toda área experimental. Para execução do experimento utilizou-se a variedade de mandioca de mesa conhecida popularmente como manteiguinha amarelinha.

Tabela 1: Análise química do solo, na profundidade 0-20 cm, área experimental UFRA-ICA, campus Belém-PA, abril de 2018.

\begin{tabular}{|c|c|c|c|c|c|c|c|c|c|c|c|c|c|}
\hline Prof. & $\mathrm{pH}$ & $\mathbf{P}$ & $\mathrm{K}$ & $\mathrm{Na}$ & Al & $\mathrm{Ca}$ & $\mathrm{Ca}+\mathrm{Mg}$ & $\mathrm{H}+\mathrm{AL}$ & SB & CTC & & \multicolumn{2}{|c|}{ Saturação } \\
\hline \multirow{2}{*}{ - } & \multirow{2}{*}{ Água } & \multirow{2}{*}{\multicolumn{3}{|c|}{$\ldots \ldots . . \mathrm{mg} / \mathrm{dm}^{3} \ldots .}}$. & & & & & & tal & Efetiva & base & $\mathrm{Al}$ \\
\hline & & & & & $\ldots \ldots$ & ........ & $\mathrm{cmolc} / \mathrm{dn}$ & $\ldots \ldots \ldots$ & \multicolumn{3}{|c|}{$\mathrm{cmolc} / \mathrm{dm}^{3}$} & V\% & $\mathrm{m} \%$ \\
\hline $0-20$ & 5,04 & 2 & 136 & 4 & 1,3 & 0,1 & 0,2 & 7,78 & 4,55 & 8,35 & 1,91 & 6,91 & 69,72 \\
\hline
\end{tabular}

Fonte: EMBRAPA (2018).

O delineamento experimental adotado foi em blocos ao acaso, com 5 tratamentos distribuídos em 5 repetições. Os tratamentos consistiram em: um tratamento controle (sem correção), correção do solo 30 dias antes, correção na ocasião do plantio, $20 \%$ de calcário no plantio e $60 \%$ durante o plantio. Como corretivo utilizou-se o calcário dolomítico (Tabela 2). A quantidade de calcário aplicado foi determinada pela análise química do solo constando de 1,644 $\mathrm{kg} \mathrm{ha}^{-1}$. As unidades experimentais foram compostas de parcelas com dimensões de 1,8 de largura e $6 \mathrm{~m}$ de comprimento espaçado em $0,9 \mathrm{~m}$ entre linhas e $1,0 \mathrm{~m}$ entre plantas, totalizando 12 plantas por unidade amostral.

Tabela 2: Tratamentos utilizados para condução de experimento em campo.

\begin{tabular}{llll}
\hline Tratamento & Épocas de aplicação de calcário & Dose $\mathbf{k g} / \mathbf{h a ́}^{-1}$ & Aplicação \\
\hline T1 & Sem calagem & 0,0 & - \\
T2 & Calagem 30 dias antes do plantio & 1,644 & 1 o \\
T3 & Calagem na ocasião do plantio & 1,644 & 2 o \\
T4 & 20\% calcário na ocasião do plantio & 1,972 & 20 \\
T5 & $60 \%$ de calcário na ocasião do plantio & 2,630 & 2 o \\
\hline
\end{tabular}

O plantio foi realizado de forma manual no mês de junho de 2018. Na área de execução do experimento havia a presença de plantas de gliricídia, utilizadas como tutor vivo para pimenta do reino. Para execução do plantio utilizou-se manivas/semente do terço médio da planta, com tamanho de $20 \mathrm{~cm}$ comprimento, em média de 6 a 8 gemas, coletadas de plantas sadias oriundas de área de plantio comercial localizado no município de São Francisco do Pará, microrregião do nordeste paraense.

As manivas-semente foram plantadas em fileiras duplas, em sulcos de $0,10 \mathrm{~cm}$ de profundidade, adotando-se o espaçamento de 0,90 cm entre fileiras de plantas 1,0 metro entre linha de planta.

A adubação de cobertura foi realizada aos 30 dias após o plantio, de forma localizada próxima ao sistema radicular. A quantidade aplicada foi realizada segundo a análise química do solo, constando de $88 \mathrm{~kg}$ de adubação nitrogenada, tendo a ureia como fonte, e $100 \mathrm{~kg}$ de fonte fosfatada na forma de Super Fosfato Simples (SFS). Pela quantidade de potássio encontrado nas análises, não foi necessário a aplicação de adubação potássica.

No estudo foram analisadas as seguintes variáveis: altura da planta; diâmetro do caule; número de folhas; peso de massa fresca da folha; número de raízes totais; comprimento de raiz; peso massa fresca do caule; número de raízes comerciais; massa de raiz comercial; massa de raízes totais; massa seca da folha; massa seca caule; massa seca de raiz total. Aos 180 após o plantio, foram selecionadas 2 plantas representativas no interior da parcela para proceder a colheita e as avaliações fotométricas: altura da planta, 
mensuradas com auxílio de uma fita métrica, entre a superfície do solo até a base do broto terminal; para avaliação do diâmetro do caule, utilizou-se um paquímetro digital realizada a $10 \mathrm{~cm}$ do solo; para determinação de número de folhas, realizou-se a contagem de todas as folhas da planta; o peso de massa fresca das folhas e peso massa fresca caule, foi determinado em balança analítica; para o número total de raízes e número de raízes comercias realizou-se contagem do todas as raízes de reserva no momento da colheita; o comprimento da raiz comerciais foi determinado com auxílio de uma fita métrica; o peso de massa fresca das raízes foi determinado em balança analítica.

Para obtenção dos valores de massa seca das folhas; massa seca de caule; e massa seca de raízes totais, o material foi posto em estufa de circulação de ar forçado, temperatura de $65^{\circ} \mathrm{C}$ por um período de 72 horas, até obtenção de matéria seca. Os dados foram organizados em planilha eletrônica Excel 2013, para a obtenção das médias dos tratamentos, sendo submetidas ao programa de softwares de análise estatístico SISVAR versão 5.6, Teste de Tukey a $5 \%$ de probabilidade.

\section{RESULTADOS E DISCUSSÃO}

Efeitos significativos dos níveis de calcário aplicados foram observados apenas nas variáveis: massa de caule, número de raiz comercial, massa de raiz comercial, peso de raiz total, massa seca da folha, massa seca do caule, massa seca da raiz. As demais variáveis não foram influenciadas pelos tratamentos.

Tabela 3: Resumo da análise de variância para as variáveis de mandioca sob efeito de épocas e doses de calcário. Altura da planta (ALT); diâmetro do caule (DC); número de folhas (NF); massa fresca da folha (MFF), PM; número de raiz comercial (NRC), número de raiz totais (NRT); massa de raiz comercial (MRC); massa de raiz total (MRT); comprimento de raiz (CR); massa seca de folha (MSF); massa seca do caule (MSC); massa seca da raiz (MSR).

\begin{tabular}{|c|c|c|c|c|c|c|c|c|c|c|c|c|c|c|}
\hline $\begin{array}{l}\text { Fonte de } \\
\text { variação }\end{array}$ & $\mathrm{GL}$ & ALP & $\mathrm{DC}$ & $\mathrm{NF}$ & MFF & $\mathrm{MC}$ & NRT & NRC & MRC & MRT & CR & MSF & MSC & MSR \\
\hline Calcário & 4 & Ns & Ns & ns & ns & $* *$ & ns & $* *$ & $* *$ & $* *$ & ns & $* *$ & $* *$ & $* *$ \\
\hline Erro & - & 0,14 & 1,01 & 11,64 & 0,06 & 0,08 & 1,22 & 0,40 & 0,22 & 0,18 & 1,46 & 5,96 & 0,03 & 0,07 \\
\hline CV \% & - & 25,54 & 15,68 & 37,41 & 84,24 & 37,27 & 26,01 & 31,72 & 27,32 & 30,99 & 16,40 & 44.99 & 45.75 & 37,04 \\
\hline
\end{tabular}

$\left({ }^{* *}\right)$ significativo ao nível de $5 \%$ de probabilidade, (ns) não significativo ao nível de $5 \%$ de probabilidade.

A variável altura da planta, não foi influenciada pelos tratamentos, porém comparados aos valores absolutos, observa-se maiores valores verificados em tratamento sem calagem com média de 1,89m de altura. Campos et al. (2013), utilizando doses crescentes de calcário, observou que as médias da altura das plantas foram significativamente superior na dose máxima de calcário de $4.781,25 \mathrm{~kg}$ ha, indicando a necessidade de percentuais maiores em relação à pesquisa.

Este valor deletério no crescimento das plantas pode estar relacionado as características genéticas da variedade em estudo, as condições edafoclimáticos em que o experimento foi conduzido, com plantio consorciado que pode ter ocorrido competição por água, luz e nutrientes. Observa-se que as entrelinhas de áreas produtoras de mandioca, no estado do Pará, são geralmente consorciadas com outras culturas, prática muito comum principalmente entre pequenos produtores, uma vez que permite o melhor aproveitamento de área da propriedade (FONTES et al., 2010).

O diâmetro do caule, assim com a altura, não obteve influência das épocas de aplicação de calcário, porém, o tratamento 1 obteve média mais elevada (21,67mm). Em experimento conduzido por Fagundes 
(2009), o mesmo verificou maior diâmetro na haste principal, atribuindo o fato à maior radiação solar incidente durante o crescimento de ramos. Rós-golla et al. (2010) ao analisarem a influência do diâmetro da maniva no desenvolvimento inicial de plantas de mandioca, constataram que a utilização de manivas com diâmetros compreendidos entre 1,8 a 2,0 cm e entre 2,5 a 3,0 cm, proporcionam estandes mais homogêneos e plantas mais desenvolvidas quando comparadas ao uso de material com diâmetro entre 1,0 a 1,2 cm. Ao comparar os dados do experimento com os dos autores, observa-se que as plantas de todos os tratamentos apresentam diâmetros que se encaixam na faixa de 1,8 a 2,0 cm, para a variedade em estudo, mostrando-se como material apto para utilização de novos cultivos, vindo a obter maior uniformidade no estande de plantas.

Os resultados relacionados ao número de folhas constataram não haver diferenças significativas entre os tratamentos adotados. No entanto, no tratamento 2 mostrou maior média (111,0 folhas/planta). Em estudos feitos por Paganini et al. (2012), ao avaliarem o desenvolvimento foliar utilizando a cultivar "Pretinha", verificaram que o número de folhas não foi influenciado pela elevação do pH promovida pela adição de calcário, pois o acompanhamento do desenvolvimento foliar em plantas associada à correção da acidez do solo, pela calagem, não são práticas comuns aos produtores de mandioca.

Pode-se inferir que os resultados do trabalho estão relacionados às condições em que o estudo fora conduzido, pois o desempenho das culturas está relacionado à capacidade genética, aos fatores edafoclimáticos e ao manejo no qual os cultivos foram submetidos.

Para a variável peso massa fresca de folha foi possível observar que não houve efeito estatístico para o incremento de matéria seca para a variedade em estudo. Entre os tratamentos, o tratamento com calagem na ocasião do plantio, obteve a maior média de massa de fresca de folha (0,63 g/planta). Cravo (2007). Em experimento montado em área recém-desmatada e queimada, constatou a tendência de reposta positiva na produção de raízes e parte aérea de macaxeira, até a dose de $1 \mathrm{t} / \mathrm{ha}^{-1}$ de calcário. Estes resultados nos qualificam inferir que, nos tratamentos adotados, no experimento, há a necessidade de adoção de novos níveis de aplicação de calcário.

Para a variável número de raízes totais, não diferiu estatisticamente entre os tratamentos, níveis e épocas de aplicação de calcário, onde a média de 16,7 raízes por planta. 0 mesmo foi constatado por um estudo feito por Martins et al. (2018), que não verificou diferença no número de raízes em função de doses de calcário variando de 3 a 5 raízes por planta. Silva et al. (2013), ao utilizar a calagem em áreas cultivadas por mandioca, não verificou influência do calcário nas raízes e mesmo a calagem melhorando as condições químicas do solo na camada superficial, não possibilitou responder a estas alterações. Esta ausência de resposta pode estar relacionada a rusticidade da cultura, ou seja, as condições iniciais do solo, mesmo sem a correção da acidez, eram suficientes para o desenvolvimento adequada da cultura.

Para a variável comprimento das raízes, segundo dados observados na Figura 7, não mostraram efeitos significativos entre os tratamentos. Porém, o tratamento sem aplicação de calcário, demonstrou maior comprimento médio de raiz com $29 \mathrm{~cm}$. Martins et al. (2018), constatam que o comprimento das raízes não foi influenciado pela quantidade de calcário aplicado, com média de $28 \mathrm{~cm}$, resultados semelhantes ao 
estudo.

Os melhores resultados encontrados para a massa de caule foram obtidos no tratamento sem aplicação de calcário, com valor médio de $1,13 \mathrm{~kg} /$ planta, superior aos demais tratamentos referentes à Figura 3. Estes resultados podem estar relacionados a características genética da cultura e rusticidade.

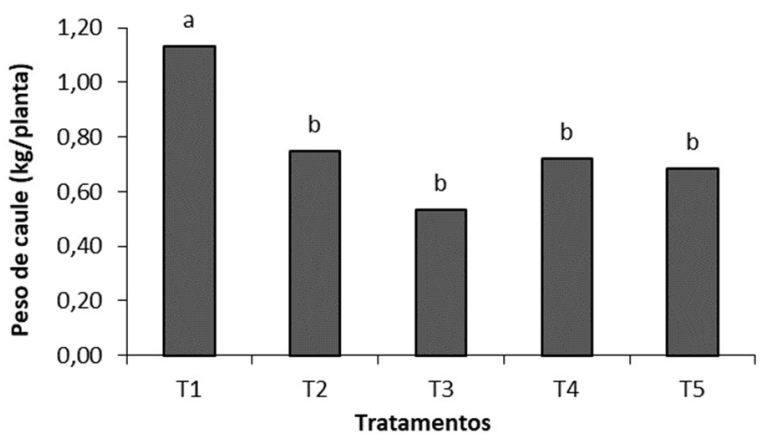

Figura 3: Peso de caule (Kg/planta) em função dos tratamentos.

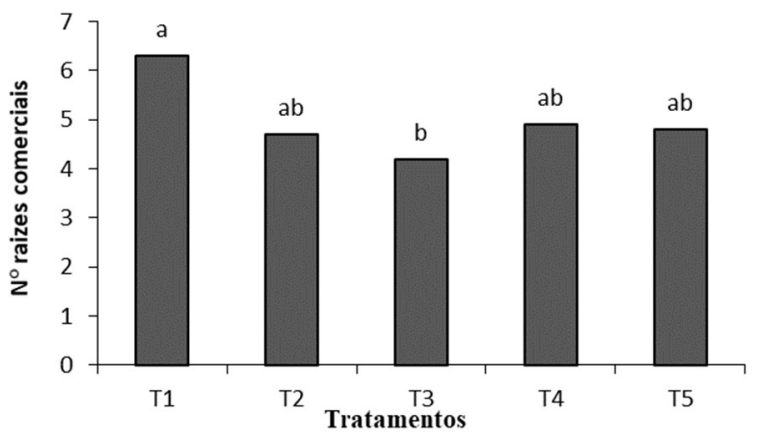

Figura 4: Médias de números de raízes comercias, aos 180 DAP.

Maiores Médias para a variável número de raízes comerciais, foram observadas no tratamento sem aplicação de calcário com média de 6,3 de raízes por planta, presente na Figura 4. Em trabalhos de Martins et al. (2018), ao compararem o desenvolvimento da cultura da mandioca, variedade vermelhinha, verificaram que possivelmente o tratamento com a menor dose de $\left(500 \mathrm{~kg} \mathrm{ha}^{-1}\right)$, proporcionou raízes mais pesadas, com até $36,6 \%$ de incremento, entretanto as raízes submetidas a aplicação de calcário de $1500 \mathrm{~kg} \mathrm{ha}^{-1}$ (maior dosagem) o peso das raízes reduziu 8,3\%. Estes resultados podem ser comparados com os dados do experimento haja vista a um maior número sem a aplicação do calcário.

Observa-se que somente as práticas culturais de preparo do solo, e as condições climáticas o qual o experimento foi conduzido, foram suficientes para que ocorressem o bom desenvolvimento das raízes.

O tratamento com aplicação de calagem aos 30 (trinta) dias antes do plantio, demonstrou melhores resultados para incremento de massa de raiz comercial, porém semelhante ao tratamento controle sem aplicação de calagem. As médias dos resultados, respectivamente, foram 1,49 kg/planta e 1,91 kg/planta, para os tratamentos sem aplicação de calcário e tratamento com aplicação de calcário aplicado aos 30 (trinta) dias antes do plantio.

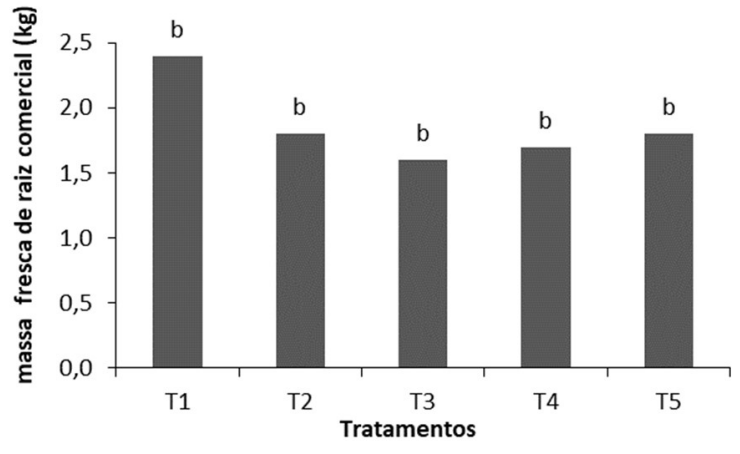

Figura 5: Médias massa fresca raiz comercial, aos 180 DAP.

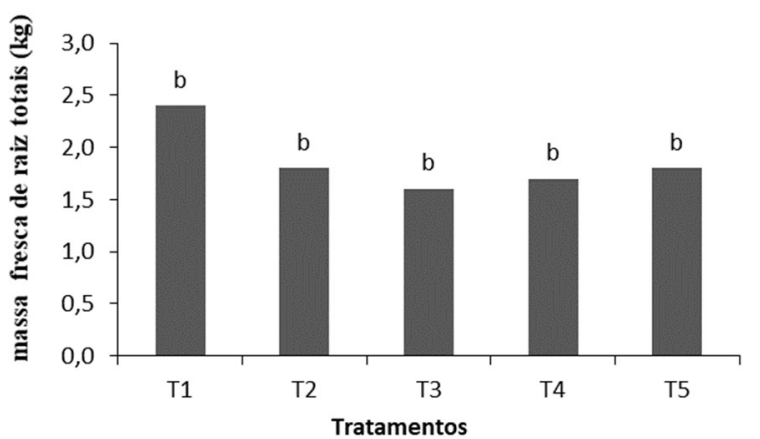

Figura 6: Médias massa fresca raiz totais $(\mathrm{kg})$, aos 180 DAP. 
Diante dos resultados de produção de raízes comerciais, a calagem pode ajudar a viabilizar sistemas de produção mais sustentáveis, com redução de custo, maior proporção de tubérculos comercializáveis e plantas mais resistentes a estresse hídrico e temperaturas elevadas (CONSORTE et al., 1994). Os resultados do estudo para a variável massa fresta de raízes totais, o tratamento sem aplicação de calcário apresentou maior incremento na matéria fresca da raiz com média $2,4 \mathrm{~kg}$ de massa na raiz.

Foi constatado por Martins et al. (2018), em experimento utilizando a variedade vermelhinha de ciclo precoce de 6 meses, que a calagem afetou a massa fresca das raízes, diferente do que ocorreu com outros parâmetros da cultura, ao comparar com plantas que não tiveram acesso ao calcário, o tratamento que recebeu a menor dose de calcário de $\left(500 \mathrm{~kg} \mathrm{ha}^{-1}\right)$ proporcionou raízes mais pesadas, entretanto as plantas submetidas a dose de $1,500 \mathrm{~kg} \mathrm{ha-}^{-1}$ (maior dose de calcário) apresentaram uma redução no peso das raízes.

Ainda em seu trabalho, Martins et al. (2018) analisando a produção de mandioca, constatou que ao utilizar a menor dose de calcário $\left(500 \mathrm{~kg} \mathrm{ha}^{-1}\right)$, a produção das raízes foi a máxima, ultrapassando quatro quilos. O tratamento com maior dosagem utilizada de calcário $\left(1500 \mathrm{~kg} \mathrm{ha}^{-1}\right)$ não promoveu diferença, em relação à Testemunha (ausência de calcário), que foi em torno de 2,4 kg.

Para a variável massa seca de folhas segundo dados apresentado na Figura 7, houve efeito significativo dos tratamentos, sendo a maior média foi alcançada no tratamento com calagem 30 (trinta) dias antes do plantio, na dosagem de calcário de $1644 \mathrm{~kg} \mathrm{ha}^{-1}$, com média de 63,89 g/planta. Valor discordante de estudo realizado por Campos et al. (2013) que verificou que a massa seca foliar aumentou de forma linear em função de calagem em coletas realizadas aos 132 e aos 181 dias após o plantio, o mesmo autor ao analisar a interação calcário x zinco observou que os nutrientes não influenciaram significativamente o acúmulo de massa de matéria seca de folhas.

Em estudo Martins et al. (2018), notaram que a calagem aplicada conforme a dose recomendada, proporcionou maior crescimento inicial e desenvolvimento da parte aérea das plantas de mandioca em resposta ao aumento das doses de calcário, consequentemente maior o acúmulo de massa seca das folhas.

Para a massa seca do caule figura 8, foi verificado efeito significativo dos tratamentos, sendo a maior média expressada no tratamento testemunha sem aplicação de calcário.

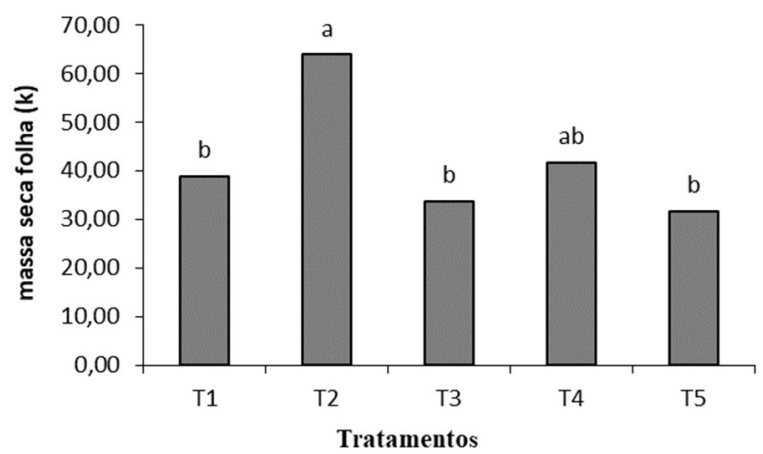

Figura 7: Massa seca folha em gramas (g), aos 180 DAP.

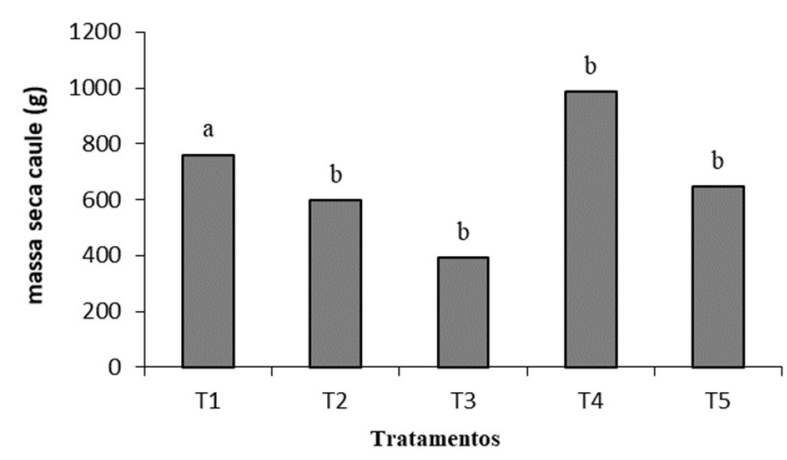

Figura 8: Média de massa seca caule (g), aos 180 DAP.

O resultado encontrado no trabalho é discordante com a maioria das literaturas citadas; como a de um autor, onde calagem proporcionou maior acúmulo de massa seca da parte aérea, conforme o aumento das doses de calcário. Já Campos et al. (2013), observa-se que a média da massa seca do caule, coletada aos 
305 dias após o plantio, também apresenta um aumento com a calagem, e esse aumento pode ser mais significativo, quando associado à adubação com zinco. Os resultados da variável massa seca de raiz, podem ser observados na Figura 9. A maior média alcançada ocorreu no tratamento testemunha sem calagem, com valor de $513 \mathrm{~g} /$ planta.

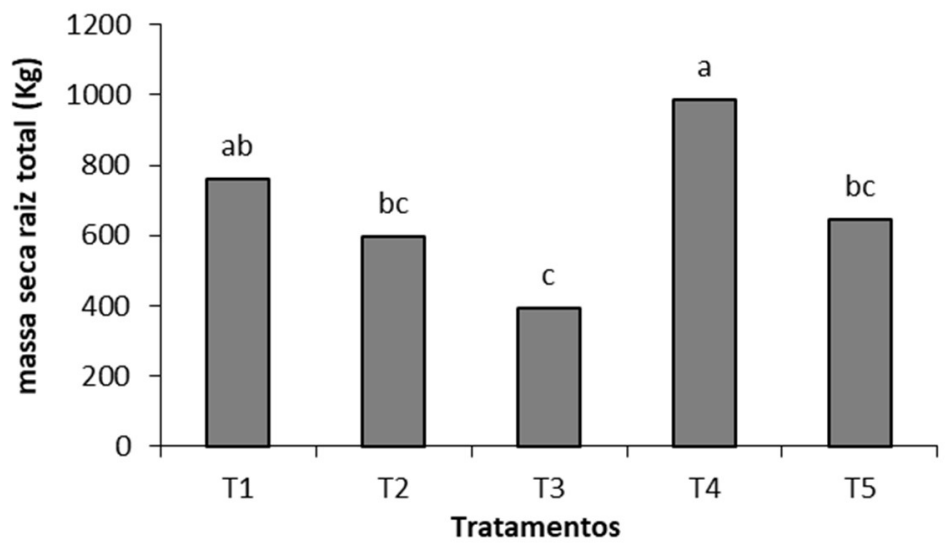

Figura 9: Massa seca raiz total (kg), aos 180 DAP.

Gonçalves et al. (2018), experimento instalado para avaliar o acúmulo de matéria seca em cultivares de mandioca percebeu que aos 7 meses de cultivo as raízes obtiveram o peso de $900 \mathrm{~g}$. Estes resultados podem ser comparados com os dados do experimento haja vista que no tratamento 4 que recebeu dose de calcário na $1,972 \mathrm{~kg} \mathrm{ha}^{-1}$ de calcário proporcionou um incremento de matéria seca de $986 \mathrm{~g}$ aos 6 meses de cultivo.

\section{CONCLUSÕES}

Os níveis de calcário aplicados não proporcionaram maiores eficiências nas variáveis produtivas da mandioca como altura da planta, diâmetro do caule, número de folhas, massa fresca de folha, número de raiz total e comprimento das raízes. Diante destes resultados, há a necessidade de maiores estudos com relação às quantidades de calcário aplicadas e épocas a serem realizadas para cultura da mandioca.

\section{REFERÊNCIAS}

ALBUQUERQUE, J. A. A.; SEDIYAMA, T.; SILVA, A. A.; ALVES, J. M. A.; FINOTO, E. L.; NETO, F. A.; SILVA, G. R..

Desenvolvimento da Cultura de Mandioca Sob Interferência de Plantas Daninhas. Planta Daninha, Viçosa, v.30, n.1, p.3745, 2012.

AGUIAR, E. B.; VALLE, T. L.; LORENZI, J. O.; KANTHACK, R. D.; FILHO, H. M.; GRANJA, N. P.. Efeito da densidade populacional e época de colheita na produção de raízes de mandioca de mesa. Bragantina, Campinas, v.70, n.3, p.561569, 2011.

ALVES, R. N. B.; MODESTO JÚNIOR, M. S.; ANDRADE, A. C. S. $O$ trio da produtividade na cultura da mandioca estudo de caso de adoção de tecnologias na região no baixo Tocantins, estado do Pará. 2008.

CONAB. Companhia Nacional de Abastecimento. Mandioca dezembro de 2017: Análise mensal. CONAB, 2017.
CAMPOS, M. F.; B S. J.; KANTHACK, R. A. D.; CRISTÓVÃO, N. N.; BRANCALIÃO, S. R.. Desenvolvimento da Mandioca em Função da Calagem e Adubação Com Zinco. In: WORSHOP AGROENERGIA, 7. Anais. São Paulo, 2013. p.1-6.

CRAVO, M. S.. Avaliação da necessidade de calagem em Terra Alta e Tracuateua. In: WORKSHOP PARA TREINAMENTO DO SOFTWARE NUTRIENT MANAGEMENT SUPPORT SYSTEM (NUMASS). Anais. Belém, 2007.

CONSORTE, J. E.; BRINHOLI, O.. Efeito da calagem e de doses de nitrocálcio em cobertura na produção de batata. Itararé, 1994.

EMBRAPA. Empresa Brasileira de Pesquisa Agropecuária. Sistema Brasileiro de Classificação de Solos. 5 ed. Brasília: Embrapa Solos, 2018. 
FAO. Food and Agriculture Organization. Produzir mais com menos: Mandioca um guia para a intensificação sustentável da produção. FAO, 2013.

FONTES, H. R.; MARTINS, C. R.. Consórcio nas entrelinhas. 2010 .

FERREIRA FILHO, J. R.; SILVEIRA, H. F.; MACEDO, J. J. G.; LIMA, M. B.; CARDOSO, C. E. L.. Cultivo, processamento e uso da mandioca: instruções práticas. Brasília: Embrapa Mandioca e Fruticultura, 2013.

GONÇALVES, Z. S.; CARVALHO, P. C. L.; PEREIRA, K. S., LEDO, C. A. S.; OLIVEIRA, M. L. A.. Acúmulo de matéria seca em cultivares de mandioca (Manihot esculenta Crantz). 2018.

KOTTEK, M.; GRIESER, J.; BECK, C.; RUDOLF, B.; RUBEL, F. World Map of the Köppen-Geiger climate classification updated. Meteorologische Zeitschrift, v.15, n.3, p.259-263, 2006.

MARTINS, J. S.; PARREIRA, M. C.; RIBEIRO, R. C.; SILVA, E. M. Calcário e sua influência no cultivo de mandioca na Amazônia Tocantina. Revista Brasileira de Agropecuária Sustentável (RBAS), Palmas, v.8, n.1, p.17-23, 2018.

MODESTO JÚNIOR, M. S.; ALVES, R. N. B.. Cultura da mandioca aspectos socioeconômicos, melhoramento genético, sistemas de cultivo, manejo de pragas e doenças e agroindústria. In: Capítulo 5 - Calagem e adubação para a cultura da mandioca. Brasília: Embrapa Amazônia Oriental, 2016. p.260.
PAGANINI, T. P.; DANIEL, V. C.; JESUS, M. H.; MIRON, G. A.; MACIEL, D. M.; SOUZA, J. E.; SILVA, A. S.; POLETTO, N. Desenvolvimento foliar, rendimento de raízes e teor de amido em mandioca cultivada com calcário, adubação orgânica e potássica. Revista Técnico Científica (IFSC), v.3, n.1, p.357-363, 2012.

RÓS-GOLLA, A.; SILVA, A. C.; NARITA, N.. Influência do diâmetro da maniva no desenvolvimento inicial de plantas de mandioca. Pesquisa \& Tecnologia, Alta Sorocabana, v.7, n.1, p.1-5, 2010

SERRAT, B. M.; LIMA, M. R.; GARCIAS, C. E.; FANTIN, E. R.; CARNIERI, I. M. R. S. A.; PINTO, L. S.. Conhecendo o Solo. Curitiba: Departamento de Solos e Engenharia Agrícola da UFPR, 2002

SILVA, A. S.; NETO, J. R.; DUART. V. M.; GARBUIO, F. J.. Atributos químicos do solo e produtividade de mandioca em função da calagem, adubação orgânica e potássica. In: MOSTRA NACIONAL DE INICIAÇÃO CIENTÍFICA E TECNOLÓGICA INTERDISCIPLINAR - MICTI, 6. Anais. Curitiba, 2013. p.1-5.

SILVA, A. R.. Cultura da Mandioca apostila: manejo e conservação do solo. Belém: Embrapa Amazônia Oriental, 2014.

VALLE, T. L.. Mandioca de mesa, macaxeira ou aipim: a hortaliça negligenciada pelo Brasil. Campinas: Instituto Agronômico (IAC), 2010.

A CBPC - Companhia Brasileira de Produção Científica (CNPJ: 11.221.422/0001-03) detém os direitos materiais desta publicação. Os direitos referem-se à publicação do trabalho em qualquer parte do mundo, incluindo os direitos às renovações, expansões e disseminações da contribuição, bem como outros direitos subsidiários. Todos os trabalhos publicados eletronicamente poderão posteriormente ser publicados em coletâneas impressas sob coordenação da Sustenere Publishing, da Companhia Brasileira de Produção Científica e seus parceiros autorizados. Os (as) autores (as) preservam os direitos autorais, mas não têm permissão para a publicação da contribuição em outro meio, impresso ou digital, em português ou em tradução. 